\title{
Improvement of Metabolic Control in Insulin Dependent Diabetics Treated with the $\alpha$-Glucosidase Inhibitor Acarbose for Two Months
}

\author{
J. Gérard, A.S. Luyckx and P.J. Lefebvre \\ Division of Diabetes, Institute of Medicine, University of Liège, Belgium
}

Summary. Acarbose, an $\alpha$-glucosidase inhibitor, delays starch digestion and inhibits intestinal sucrase and maltase activity. Twenty-eight insulin dependent diabetics were given Acarbose $(3 \times 100 \mathrm{mg}$ daily) over a two month period, preceded and followed by a two month placebo period. Acarbose reduced post-breakfast and post-dinner blood glucose values by $25 \%(p$ $<0.001)$ and $24 \%(p<0.05)$ respectively. It also significantly reduced mean daily blood glucose by $18 \%(p$ $<0.05$ ) and mean amplitude of glycaemic excursions from $8.0 \pm 0.6$ to $5.5 \pm 0.4 \mathrm{mmol} / 1(p<0.0005)$. Weight did not change significantly. Daily caloric and carbohydrate intake remained constant throughout the study while insulin requirements decreased slightly but significantly. Out of the 28 patients, 18 had absent while ten had slight residual $\mathrm{B}$ cell function as assessed by plasma C-peptide measurements. Treatment with Acarbose did not significantly affect residual $B$ cell function. The beneficial effect of Acarbose on blood glucose control was seen in patients both with and without residual $B$ cell secretion. The major side-effect was flatulence which was never severe enough to interrupt treatment, but led to a $50 \%$ reduction of the dose in one patient. It is concluded that Acarbose represents a useful additional means of improving metabolic control in insulin dependent diabetics.

Key-words: Acarbose, diabetes, insulin dependent diabetes, metabolic control.

Acarbose (BAY-g-5421) is a complex oligosaccharide of microbial origin [1] which delays starch digestion and which has anti-sucrase and anti-maltase activities [2-4]. Short-term metabolic studies have suggested that Acarbose may be a useful additional treatment for diabetic patients [5-7]. The aim of the present study was to investigate the potential benefits of Acarbose in insulin dependent diabetics over a period of two months. The experiment was conducted with a single-blind protocol in which the patients were given a placebo for two months before and two months after the treatment period. Clinical and biochemical tolerance was simultaneously investigated. In addition, residual B cell secretion was assessed by plasma $\mathrm{C}$-peptide measurements in order to detect any effect of Acarbose and also to see if residual $\mathrm{B}$ cell function would influence the effect of Acarbose on diabetic control.

\section{Patients and Methods}

\section{Patients}

Thirty-two insulin dependent diabetics entered the study; four subjects dropped out, two for non-adherence to the protocol, two for recurrence of previous bowel problems during the first placebo period. The complete study was therefore performed on 28 patients, 14 males and 14 females. The details of the patients studied are giv$\mathrm{en}$ in Table 1. Mean duration of diabetes was $11.8 \pm 1.4$ (SEM) years in males and $12.8 \pm 1.7$ years in females. The mean daily dose of insulin was $50 \pm 8$ (SEM) units in males and $47 \pm 4$ units in females. The patients were instructed to follow their usual dietary regimen.

\section{Experimental Protocol}

The study was approved by the Human Investigation Ethical Committee of our Institution. All patients were carefully instructed about the aims of the study and consented to participation. All the subjects investigated were out-patients regularly attending our University Diabetic Clinic. They continued to be seen every two months by their usual physicians who agreed to their participation in the study. In addition, all patients were seen every two months by one of us. Dietary interviews were performed before and every two months during the study. The study comprised three consecutive periods of two months each. During the first period, the patients received a placebo tablet three times daily indistinguishable from 
Table 1. Details of patients studied ${ }^{\mathrm{a}}$

\begin{tabular}{llllll}
\hline & $\begin{array}{l}\text { Age } \\
\text { (years) }\end{array}$ & $\begin{array}{l}\text { Weight } \\
(\mathrm{kg})\end{array}$ & $\begin{array}{l}\text { Duration of diabetes } \\
\text { (years) }\end{array}$ & $\begin{array}{l}\text { Daily insulin dose } \\
\text { (units) }\end{array}$ & $\begin{array}{l}\text { Duration of insulin therapy } \\
\text { (years) }\end{array}$ \\
\hline Mean & 46 & 69 & 12.3 & 48 & 10.0 \\
SD & 14 & 14 & 5.8 & 22 & 6.3 \\
SEM & 3 & 3 & 1.1 & 4 & 1.2 \\
\hline
\end{tabular}

a Individual data are available from authors on request

Table 2. Dietary intake estimated from interviews during the study

\begin{tabular}{lllll}
\hline & $\begin{array}{l}\text { Carbohydrate } \\
(\%)\end{array}$ & $\begin{array}{l}\text { Protein } \\
(\%)\end{array}$ & $\begin{array}{l}\text { Lipid } \\
(\%)\end{array}$ & $\begin{array}{l}\text { Daily caloric intake } \\
\text { (MJ) }\end{array}$ \\
\hline Pretreatment & $36.4 \pm 6.1$ & $16.8 \pm 2.7$ & $46.8 \pm 7.6$ & $8.511 . \pm 2.257$ \\
First placebo period & $38.6 \pm 6.1$ & $17.6 \pm 2.3$ & $43.8 \pm 6.6$ & $7.746 \pm 2.466$ \\
Acarbose period & $38.2 \pm 6.7$ & $17.3 \pm 3.0$ & $43.5 \pm 7.1$ & $8.310 \pm 2.650$ \\
Second placebo period & $37.1 \pm 6.5$ & $17.6 \pm 3.1$ & $45.0 \pm 6.6$ & $8.189 \pm 2.504$ \\
\hline
\end{tabular}

Date are expressed as mean $\pm \mathrm{SD}$. None of the values is significantly different

Acarbose tablets. During the second period, they received Acarbose $100 \mathrm{mg}$ three times daily. During the last period of the study, patients were given placebo again. The tablets were taken at the beginning of each main meal (breakfast, lunch and dinner). During the first week of each period, the patient was advised to take only half of the dose, in order to reduce any troublesome bowel effects. At the beginning of the study and at the end of each period, the patients spent one day in our Metabolic Unit during which blood glucose and C-peptide profiles were performed. Blood samples were taken through an indwelling cannula at $0800,1030,1200,1430$, 1800,2030 and $2130 \mathrm{~h}$. Breakfast, lunch and dinner were taken immediately after collecting the 0800,1200 and $1800 \mathrm{~h}$ blood samples, while snacks were taken after collecting the 1030,1430 and $2030 \mathrm{~h}$ blood samples. On each test day, blood was also collected for $\mathrm{HbA}_{\mathrm{lc}}$ determination and for routine haematological and biochemical tests. During each month of the study, the patients were interviewed with particular reference to gastro-intestinal tolerance and other side-effects.

\section{Laboratory Investigations}

Venous blood glucose was determined using the hexokinase method adapted to the Technicon autoanalyzer [8]. Plasma C-peptide was determined by radioimmunoassay according to Heding [9]. Using this assay, the minimal detection value was $0.01 \mathrm{pmol} / \mathrm{ml}$ and the interassay variation coefficient $6.3 \% . \mathrm{HbA}_{\mathrm{lc}}$ was evaluated using isoelectric focussing [10]. A full blood count was performed with an automated counter. Plasma bilirubin, transaminases, alkaline phosphatases, creatinine and proteins, blood urea and nitrogen and serum iron, calcium, sodium, magnesium and triglycerides were determined using standard procedures (Laboratory of Clinical Biochemistry of the University of Liège, Professor C. Heusghem).

\section{Calculations and Statistical Methods}

The mean amplitude of glycaemic excursions (MAGE) and the "M" value (an index of diabetic control) were calculated from the blood glucose values of the daily profiles according to Service et al. [11] and Schlichtkrull et al. [12] respectively. Statistical analysis was performed using Student's t test for paired and unpaired data [13]. Results are expressed as mean \pm SEM.

\section{Results}

\section{Tolerance and Side-Effects}

Body weight remained similar throughout the study: $68.9 \pm 2.6 ; 67.7 \pm 2.4 ; 67.5 \pm 2.3$ and $67.2 \pm 2.4 \mathrm{~kg}$ before the trial and at the end of each experimental period, respectively. None of these values was significantly different. Similarly, arterial blood pressure remained unchanged. During the first placebo period, three patients complained of moderate flatulence, three had an increased tendency to hypoglycaemia and three others reported that hypoglycaemia was less frequent. During the two month Acarbose period, 23 patients ( $82 \%$ ) reported flatulence which was considered as minor by 13 patients and slightly uncomfortable by ten. Nevertheless, all patients volunteered to complete the study. The Acarbose dose was reduced to $50 \mathrm{mg}$ three times daily in one patient who complained of abdominal discomfort. During the Acarbose period, three patients noticed softer stools and one had diarrhoea; only two patients reported no side-effects at all. During the second placebo period, flatulence disappeared in all patients except two, while a tendency to constipation was reported by three patients.

No change was observed in routine biochemical and haematological parameters which were all in the normal range.

As shown in Table 2, the total caloric intake, as well as the proportion of protein, carbohydrate and lipid estimated by dietary interviews, remained similar throughout the study. No loss of appetite was reported. The mean insulin requirements were $48 \pm 4$ $\mathrm{U} /$ day before and during the first placebo period 


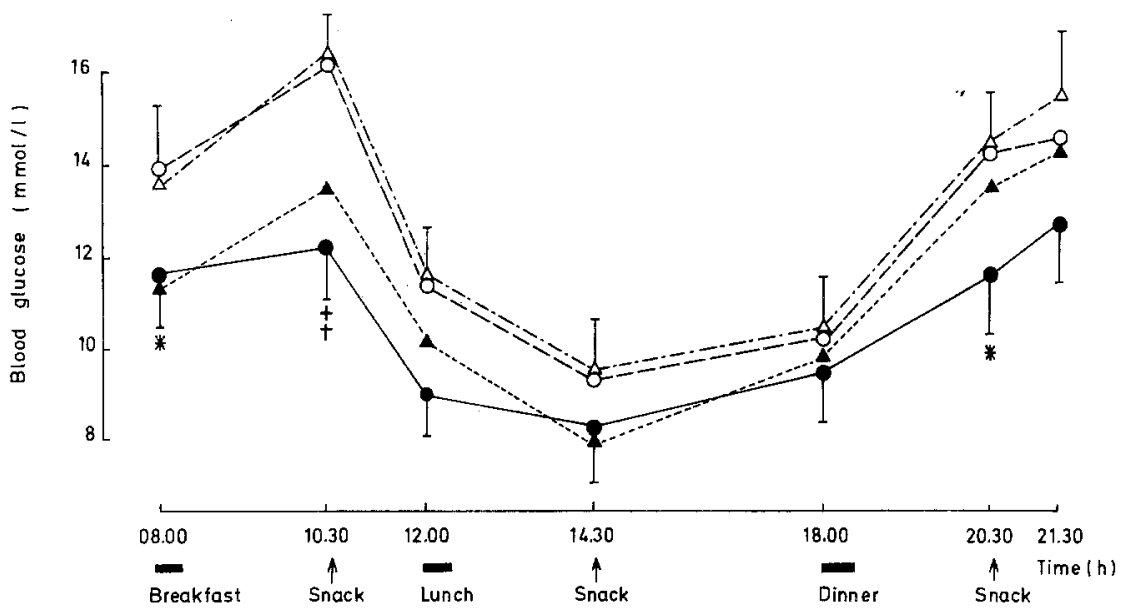

Fig. 1. Daily blood glucose profiles before treatment $(\mathrm{O}----\mathrm{O})$, during the first placebo period $(\Delta-\cdot-\cdot-\Delta)$, the Acarbose period ( placebo period ( $\mathbf{A}-\mathbf{\Lambda})$. Results are given as mean \pm SEM for the pre-treatment and Acarbose periods. The SEM for the two placebo periods are of similar magnitude and are not shown. * and $\uparrow$ correspond to $p<0.05$ and $p<0.001$ when Acarbose is compared with the pre-treatment period. + corresponds to $p<0.001$ when Acarbose is compared with the first placebo period compared with a slight but significant reduction when Acarbose was given ( $46 \pm 4 \mathrm{U} /$ day; $p<0.02$; paired comparison). Blood glucose values below $2.8 \mathrm{mmol} / 1$ were observed on four occasions on four patients during the second placebo period compared with nine occasions in seven patients during the treatment with Acarbose. No severe hypoglycaemic episodes were observed in any patient throughout the six month study period.

\section{Effects of Acarbose on Diabetes Control}

Ambulatory Blood Glucose Levels and Glycosuria. At routine clinic visits, the post-prandial mid-morning blood glucose levels were $9.2 \pm 1.0 \mathrm{mmol} / \mathrm{l}$ in the first placebo period compared with $6.8 \pm 0.8 \mathrm{mmol} / 1$ when Acarbose was given $(p<0.02$; paired comparison). They increased to $8.2 \pm 0.8 \mathrm{mmol} / 1$ in the second placebo period. The mid-morning urinary glucose levels were $20 \pm 4 \mathrm{~g} / \mathrm{l}$ in the first placebo period and $9 \pm 3 \mathrm{~g} / 1$ during treatment with Acarbose $(p$ $<0.025)$. During the second placebo period they increased to $18 \pm 3 \mathrm{~g} / 1(p<0.05)$.

Blood Glucose Daily Profiles. As illustrated in Figure 1 , the blood glucose profiles at the beginning of the study and at the end of the first placebo period were virtually identical. In contrast, Acarbose significantly reduced the fasting blood glucose, the post-breakfast blood glucose and the post-dinner blood glucose. At the end of the second placebo period, blood glucose tended to return to the previous pattern but fasting and post-breakfast blood glucose remained significantly lower than during the first placebo period $(p<0.05)$.

As shown in Figure 2, the mean daily blood glucose values, derived from the blood glucose profiles, were significantly lower $(10.7 \pm 0.8 \mathrm{mmol} / \mathrm{l}) \mathrm{du}-$
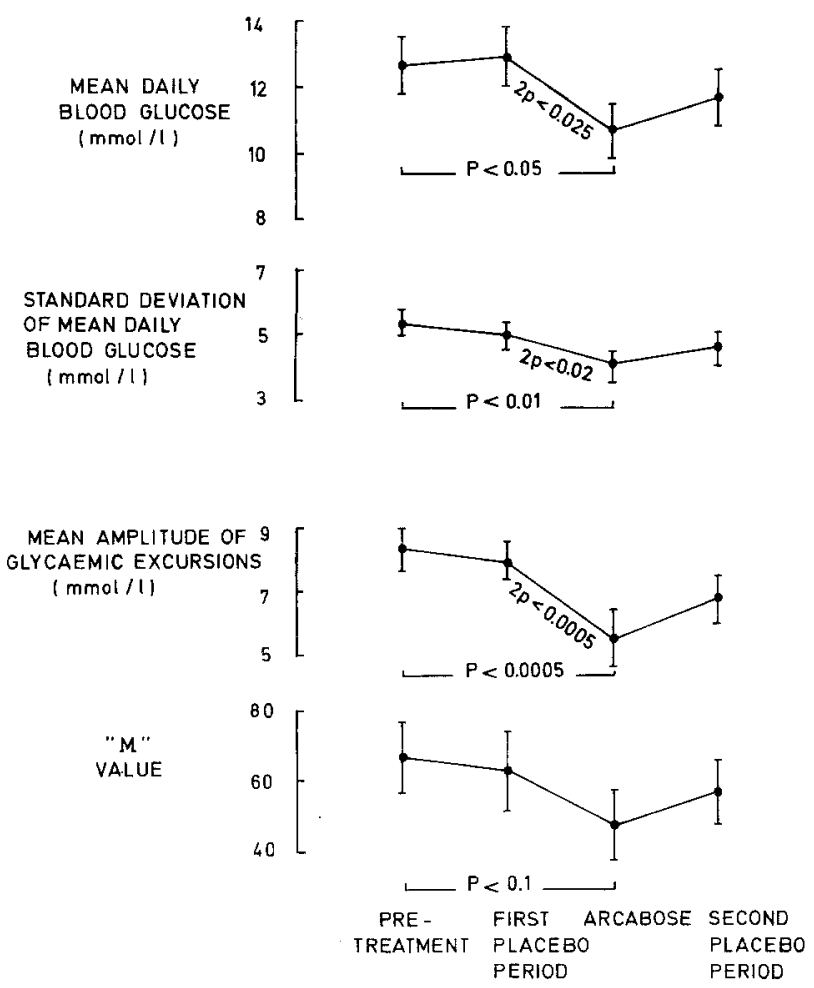

Fig. 2. Daily blood glucose, the standard deviations of mean daily blood glucose, mean amplitude of glycaemic excursions (MAGE) and " $M$ " value of Schlichtkrull et al. [12] during the first placebo period, the Acarbose period and the second placebo period. Results are given as mean $\pm \mathrm{SEM}$

ring the Acarbose period compared with $12.8 \pm$ $0.9 \mathrm{mmol} / 1$ (pre-treatment), $13.1 \pm 0.9 \mathrm{mmol} / 1 \mathrm{dur}-$ ing the first placebo period and $11.7 \pm 0.9 \mathrm{mmol} / 1$ during second placebo period. The mean of the standard deviations of the mean daily blood glucose values (an index of blood glucose fluctuations in a given day) was significantly lower during the Acarbose period: $4.1 \pm 0.4$ versus $5.4 \pm 0.4 \mathrm{mmol} / \mathrm{l}$ in the pre-treat- 


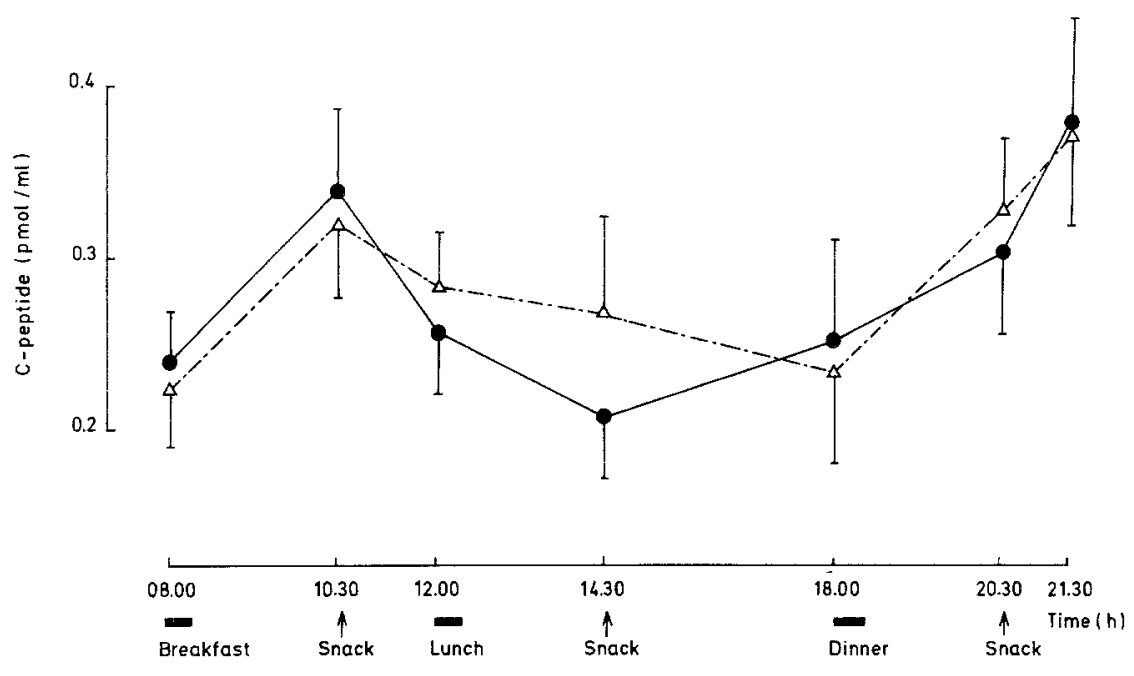

Fig. 3. Plasma C-peptide daily profiles at the end of the first placebo period $(\Delta \cdot-\cdot-\cdot-\Delta)$ and at the end of the Acarbose period ( - ) in the patients with residual B cell function. Results are expressed as mean \pm SEM ment period and $5.0 \pm 0.4 \mathrm{mmol} / \mathrm{l}$ in the first placebo period. The MAGE index was significantly reduced during the Acarbose period: $5.5 \pm 0.4$ versus $8.4 \pm$ $0.7 \mathrm{mmol} / 1$ (pre-treatment) and $8.0 \pm 0.6 \mathrm{mmol} / 1$ in the first placebo period. A MAGE index exceeding $6.6 \mathrm{mmol} / 1$ [11] was recorded in 16 patients in the pretreatment period, in 22 in the first placebo period and in 12 in the second placebo period. In contrast, such high MAGE indices were observed in only five patients during treatment with Acarbose $(p<0.001)$. The mean " $M$ " value of Schlichtkrull et al. [12] was $67 \pm 10$ (pre-treatment), $63 \pm 11$ during the first placebo period and $57 \pm 9$ during the second placebo period. During Acarbose it was $48 \pm 10(p<0.1$ versus pre-treatment). $\mathrm{HbA}_{\mathrm{lc}}$ levels did not change significantly throughout the study: $8.1 \pm 0.3 \%$ (pre-treatment), $8.4 \pm 0.3 \%$ (first placebo period), $8.1 \pm 0.3 \%$ (Acarbose) and $8.5 \pm 0.4 \%$ (second placebo period).

\section{Acarbose and Residual B Cell Function}

The 28 patients were examined for residual $B$ cell function by measuring plasma C-peptide in the samples collected for the blood glucose profiles. Those patients with a fasting plasma C-peptide $\geqslant 0.1$ $\mathrm{pmol} / \mathrm{ml}$ and a $2 \frac{1}{2} \mathrm{~h}$ post-prandial value $\geqslant 0.15$ $\mathrm{pmol} / \mathrm{ml}$ were considered to have residual $\mathrm{B}$ cell function. According to these criteria, ten patients had evidence of residual $\mathrm{B}$ cell function while 18 did not. Their mean duration of diabetes was $11.3 \pm 2.0$ and $13.9 \pm 1.3$ year (NS) and their mean insulin requirements were $37 \pm 6$ and $54 \pm 5 \mathrm{U} /$ day respectively $(p<0.025)$.

In the ten patients considered to have residual $\mathrm{B}$ cell function, the mean daily plasma C-peptide values were not significantly different during the three experimental periods: $0.302 \pm 0.037,0.285 \pm 0.037$ and $0.220 \pm 0.031 \mathrm{pmol} / \mathrm{ml}$ respectively. As shown in Figure 3 , the mean daily plasma C-peptide profiles were similar during the first placebo and the Acarbose periods.

The improvement in diabetic control already mentioned in the 28 patients as a whole is still observed when the data are analysed separately for the two subgroups. However, the lowering of post-dinner blood glucose values was observed only in the patients with residual $\mathrm{B}$ cell secretion.

\section{Discussion}

One of the difficulties of insulin treatment is the adequate control of post-prandial rises in blood glucose. Recently beneficial effects have been reported from the enrichment of food with naturally occurring fibre, such as guars and pectins [14-17]. A new approach has beein developed by the isolation of complex oligosaccharides of microbial origin possessing $\alpha$-glucosidase inhibitory properties. Among these compounds, Acarbose has been selected for its maximal inhibitory effects on starch digestion and sucrose absorption [4]. Preliminary studies have indicated that Acarbose reduces the rise in blood glucose following a meal or an oral sucrose load $[3,18,19]$. Until now, the potential benefit of Acarbose in insulin treated diabetics has been investigated in two short-term studies only. Walton et al. [6] reported a double-blind study in seven diabetics receiving Acarbose or placebo on two days at weekly intervals. They observed that Acarbose diminished the post-prandial increases in blood glucose, lactate and pyruvate concentrations. Sachse and Willms [5] treated 12 insulin dependent diabetics for one week in a double-blind cross-over study comparing Acarbose with placebo. They reported that Acar- 
bose lowered the mean and the maximal blood glucose values as well as the "integrated blood glucose response".

In the present investigation, Acarbose given for two months clearly improved blood glucose control. Indices of stability were also improved, another beneficial effect of the treatment which was obtained despite the low carbohydrate intake of our patients. $\mathrm{HbA}_{\mathrm{lc}}$ levels did not change significantly despite the clear-cut effect on blood glucose. Two possible explanations are (1) our patients had $\mathrm{HbA}_{1 \mathrm{c}}$ in the middle range for the method at the beginning of the study and (2) under these conditions, a longer treatment period might be necessary to reflect clearly the improved control by $\mathrm{HbA}_{\mathrm{lc}}$ measurements. The continued improvement of diabetic control observed at the end of the second placebo period may have been due to the increased supervision of the subjects during the study and greater adherence to their diet and insulin regimen; however we cannot rule out long-term changes induced by Acarbose such as altered gut morphology [20].

Acarbose did not significantly modify the endogenous insulin response to food ingestion in patients with residual $\mathrm{B}$ cell function. This observation is interesting in view of the significant lowering of the postprandial blood glucose rises, suggesting that Acarbose may not interfere with other mechanisms, such as the entero-insulin axis, controlling insulin release in these patients. The beneficial effect of Acarbose on blood glucose control is seen in patients with or without residual B cell secretion, although it may be slightly more pronounced in the former. This latter observation is consistent with the marked effect of Acarbose reported in non-insulin dependent diabetics [5, 7]. Nevertheless, the unequivocal effect of Acarbose in patients with undetectable B cell function indicates that these patients may also benefit from this treatment.

No significant weight change was observed during the study. This, in conjunction with the constant food intake throughout the study, suggests that Acarbose, under our experimental conditions, mainly acts by delaying rather than inhibiting carbohydrate $a b-$ sorption.

During the two month Acarbose treatment period, moderate hypoglycaemia occurred slightly more often than during the other study periods, despite a modest but significant reduction in insulin requirements. Physicians and patients should be advised that adding Acarbose to the treatment of insulin treated diabetics may favour hypoglycaemia and a moderate reduction of insulin dose may be necessary.

As reported in previous studies [5, 7, 18, 19], the most disturbing side-effect of Acarbose is flatulence.
This may be attributed to colonic fermentation of undigested carbohydrates. However, this phenomenon should be quantitatively modest since there was no malabsorption or significant weight loss during the study. These side-effects never required interruption of the trial and necessitated a reduction of the Acarbose dose to $150 \mathrm{mg}$ daily in only one subject.

In conclusion, by reducing post-prandial increases in blood glucose, mean daily blood glucose and the mean amplitude of glycaemic excursions, Acarbose, given at a dose of $100 \mathrm{mg}$ three times daily [2], represents a useful additional means of improving metabolic control in insulin treated diabetics. Its use for two months was clinically well tolerated and its major side-effect (flatulence) was accepted by the vast majority of patients.

Acknowledgments. We thank Dr. I. Hillebrand, Bayer A. G., Wuppertal, FRG, for useful advice and discussion and for the supply of Acarbose and placebo tablets. We acknowledge the help of Dr. Lennes for the statistical analysis of the data. We are indebted to M. E. Loumaye, Y. Claessens and C. Borremans for technical assistance and to E. Vaessen-Petit for expert secretarial help. A. Luyckx is Maître de Recherches of the F. N. R. S. (Belgium).

\section{References}

1. Schmidt DD, Frommer W, Junge B, Muller L, Wingender W, Truscheit E (1977) $\alpha$-Glucosidase inhibitors. Naturwissenschaften 64:535

2. Puls W, Keup U, Krause HP, Thomas G, Hoffmeister R (1977) Glucosidase inhibition. Naturwissenschaften 64:536

3. Caspary WF (1978) Sucrose malabsorption in man after ingestion of $\alpha$-glucosidehydrolase inhibitor. Lancet 1: 1231-1233

4. Caspary WF, Graf S (1979) Inhibition of human intestinal $\alpha$ glucosidehydrolases by a new complex oligosaccharide. Res Exp Med 175: 1-6

5. Sachse G, Willms B (1979) Effect of the $\alpha$-glucosidase inhibitor BAY-g-5421 on blood glucose control of sulphonylurea-treated diabetics and insulin-treated diabetics. Diabetologia 17: 287-290

6. Walton RJ, Sherif IT, Noy GA, Alberti KGMM (1979) Improved metabolic profiles in insulin-treated diabetic patients given an alpha-glucosidehydrolase inhibitor. $\mathrm{Br}$ Med $\mathrm{J} \mathrm{L}$ : 220-221

7. Laube Von H, Fouladfar M, Aubell R, Schmitz H (1980) Zur Wirkung des Glukosidasehemmers Bay g 5421 (Acarbose) auf das Blutzuckerverhalten bei adipösen Erwachsenendiabetikern. Arzneim Forsch 30: 1154-1157

8. Schmidt FH (1961) Enzymatic determination of glucose and fructose simultaneously. Klin Wochenschr 39: 1244

9. Heding LG (1975) Radioimmunological determination of human C-peptide in serum. Diabetologia 11:541-548

10. Schoos R, Schoos-Barbette S, Lambotte C (1978) Dosage of hemoglobin $A_{1 c}$ by isoelectrofocussing. Clin Chim Acta 86: 61-65

11. Service FJ, Molnar GD, Rosevear JW, Ackerman E, Gatewood LC, Taylor WF (1970) Mean amplitude of glycemic excursions, a measure of diabetic instability. Diabetes 19:644-655

12. Schlichtkrull S, Munck O, Jersild M (1961) The M value, an index of blood sugar control in diabetics. Acta Med Scand 177: 95-99 
13. Snedecor GW (1976) Statistical methods, 5th edn. Iowa State University Press, Ames

14. Jenkins DJA, Leeds AR, Wolever TMS, Goff D, Alberti KGMM, Gassul MA, Hockaday TDR (1976) Unabsorbable carbohydrates and diabetes : decreased post-prandial hyperglycaemia. Lancet 2: 172-174

15 Jenkins DJA, Taylor RH, Nineham R, Goff DV, Bloom SR, Sarson D, Alberti KGMM (1979) Combined use of guar and Acarbose in reduction of postprandial glycaemia. Lancet 2:924 927

16. Jenkins DJA, Wolever TMS, Ninehma R, Sarson DL, Bloom SR, Ahern J, Alberti KGMM, Hockaday TDR (1980) Improved glucose tolerance four hours after taking guar with glucose. Diabetologia 19:21-24

17. Jenkins DJA, Wolever TMS, Hockaday TDR, Leeds AR, Haworth R, Bacon S, Apling EC, Dilawari JB (1977) Treatment of diabetes with guar gum. Lancet 2: 779-780

18. Hillebrand I, Boehme K, Franck G, Fink H, Berchtold P (1979) The effects of the $\alpha$-glucosidase inhibitor BAY g 5421 (Acarbose) on meal-stimulated elevations of circulating glucose, insulin and triglyceride levels in man. Res Exp Med 175:81-86
19. Hillebrand I, Boehme K, Frank G, Fink H, Berchtold P (1979) The effects of the $\alpha$-glucosidase inhibitor BAY g 5421 (Acarbose) on postprandial blood glucose, serum insulin, and triglyceride levels: dose-time-response relationships in man. Res Exp Med 175: 87-94

20. Caspary WF, Graf S (1979) Inhibition of human intestinal $\alpha$ glucoside-hydrolases by a new complex oligosaccharide. Res Exp Med 175: 1-6

Received: 6 January 1981

and in revised form: 27 May 1981

Dr. Pierre Lefèbvre

Division of Diabetes

Institute of Medicine

Hôpital de Bavière

Boulevard de la Constitution 66

B-4020 Liège, Belgium 